\title{
ANTONIO ALATORRE O EL PLACER DE HACER LAS COSAS BIEN
}

Me toca dar una visión de la labor de quien considero no sólo mi profesor, mi antecesor y mi colega, sino, ante todo, mi maestro, en el sentido más rico y amplio de quien crea escuela y cuyas enseñanzas no terminan en el salón de clase. Aunque no sé si Antonio lo cree así, pues trabajo en temas aparentemente lejanos de los suyos, me declaro su discípula porque lo que he sabido investigar, lo que he escrito y dicho bien en mi vida, lo he podido hacer gracias a que Alatorre me dio las pautas para encontrar mi camino. Aprendí con él dos cosas indispensables: por un lado, supe que la crítica y la autocrítica son esenciales para estimular el pensamiento sano y, por otro, aprendí también, paso a paso, a profundizar y pulir lo que uno hace. Me ayudó a acercarme lo más posible, no a mi verdad ni a su verdad, sino a buscar verdades probables.

Antonio Alatorre llegó al Colegio de México en 1948 como estudiante becario. Muy pronto, en 1950, Alfonso Reyes lo nombró profesor del entonces llamado "Centro de Estudios Filológicos". Al terminar el año de 1950 y hasta julio de 1952 estuvo becado en España y en Francia como investigador.

De su periodo de formación en El Colegio, en diversas ocasiones ha dejado en claro la importancia que tuvieron para él las enseñanzas de Raimundo Lida, fundador en 1947 del hoy Centro de Estudios Lingüísticos y Literarios. De ese periodo de formación, él mismo dice: "en cuanto ente profesional, en cuanto investigador de cosas de lengua y de literatura, en cuanto miembro de una institución docente - y también, mucho, en cuanto simple ser humano- mi paradigma es Raimundo Lida"'.

${ }^{1}$ Inauguración de la Sala Raimundo Lida, Anexo de la NRFH, 33 (1984), núm. 2

NRFH, XL (1992), núm. 1, 3-9 
Para entender esto debemos remontarnos en el tiempo y saber que Antonio Alatorre nació en Autlán, Jalisco, el 25 de julio de 1922; esto quiere decir que tenía 25 años cuando llegó al Colegio. Su formación anterior, en un "instituto religioso", le dio la posibilidad de acercarse a temas, materias y lenguas muy variadas, desde latín, griego, filosofía y teología hasta aprender música y a tocar el piano. Después pasó dos años en Guadalajara, de 1943 a 1945, en los que convivió con escritores jaliscienses de la talla de Juan José Arreola y Juan Rulfo. " Todo lo que en Arreola era exuberancia - dice Antonio-, era silencio y concentración en Rulfo" "2. Con Arreola hizo la revista literaria Pan y con él se adentró en la lectura voraz de literaturas que le eran desconocidas, en especial la francesa. "Mi organismo interior - afirma Antonio- comenzó, con la voracidad del hambriento crónico, a llenar sus inmensos vacíos y a asimilar platillo tras platillo, en la alegría [...] y sin indigestión alguna. Y todo, o casi todo, fue regalo de Arreola"'3.

En 1946 Alatorre vino a la ciudad de México para estudiar simultáneamente Derecho (carrera que dejó pronto) y Letras en la Universidad Nacional Autónoma de México. Durante esos mismos dos años comenzó un valioso entrenamiento en el departamento técnico del Fondo de Cultura Económica, editorial que dirigía Daniel Cosío Villegas, y en la que colaboraban destacados emigrados republicanos españoles, como el clasicista y bibliógrafo Agustín Millares Carlo, Joaquín Díez-Canedo, Eugenio Ímaz, Luis Alaminos y tantos otros. "En el Fondo - cito de nuevobebí verdadera cultura. El Fondo fue mi verdadera preparación

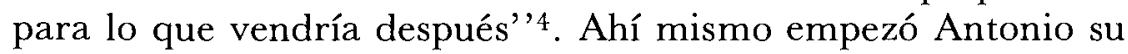
espléndida labor de traductor.

Todos estos conocimientos tan variados, pero tan ricos - los del seminario, los de la vida literaria de Guadalajara, los de su labor editorial de corrector y de traductor en el Fondo- le sirvieron a Alatorre para aprovechar de manera notable los tres años que estudió con Raimundo Lida. Con Lida desarrolló sus grandes dotes de filólogo. Su amor por la palabra se manifestó en sus varios aspectos: en entender el desarrollo y el funcionamiento del

2 "Presentación" a la reedición de la revista Pan (1945-1946), F.C.E., México, 1985, p. 225.

${ }^{3}$ Ibid., p. 221.

4 "Testimonio de Antonio Alatorre", en Clara E. Lida y José Mate. SAnz, El Colegio de México: una hazaña cultural, 1940-1962, El Colegio de México, México, 1990, p. 242, n. 12. 
lenguaje, en percibir los mecanismos que hacen de una obra literaria una obra de arte, en situarla - para comprenderla mejoren su contexto histórico, en valorar la crítica inteligente, en concentrar su atención en lo esencial de la relación entre el lenguaje y el pensamiento y, por lo tanto, en desechar el discurso vano y superfluo, la palabrería y la incoherencia.

En 1953, Raimundo Lida se fue de México a la Universidad de Harvard y Alatorre quedó, de pronto, muy sorprendido, a cargo de la dirección del Centro de Estudios Filológicos, tarea que desempeñó durante casi 20 años, hasta 1972. Pero aquel joven de 28 o 29 años, a partir de ese momento no sólo tuvo que ser Director del Centro, sino también tuvo que encargarse de una magna labor, totalmente deslindada de la dirección: editar la Nueva Revista de Filología Hispánica, fundada también por Lida en 1947. Esta revista ha contribuido a forjar una parte sustancial del valor y del prestigio de El Colegio de México, porque ha demostrado, desde 1947 hasta la fecha, que en un país como el nuestro sí se puede realizar y sostener una labor intelectual y editorial sistemática, de la más alta calidad, comparable con las mejores del mundo.

Fue, pues, a partir de esos años tempranos cuando Antonio Alatorre empezó a desarrollar una obra propia como editor, como traductor, como filólogo y crítico creativo y original y como profesor de múltiples generaciones de estudiantes.

Dos rasgos distintivos se destacan en la obra de Antonio. Ya dije que uno es el de ser, en todas estas tareas intelectuales, un Maestro. El otro, muy importante, está sintetizado en el hermoso verso de Antonio Machado "Despacito y buena letra:/el hacer las cosas bien/importa más que el hacerlas". Yo identificaría, pues, en general, el quehacer intelectual de Antonio con el placer de hacer las cosas bien.

La obra de Alatorre es en gran parte, la construcción de esta Nueva Revista. En ella se refleja algo indispensable para el conocimiento: el saber evaluar, seleccionar, elegir y, en este caso, publicar sólo lo que es bueno y saber rechazar lo que es malo. Con Raimundo Lida, primero, y con Antonio Alatorre, después, a la cabeza, la $N R F H$ ha sido - y sigue siendo- un foro abierto a todo aquello que es valioso dentro del estudio del lenguaje y d $\epsilon$ la literatura en lengua española.

Sabemos que Alatorre editaba la NRFH tan inmejorablemen. te que si llegaba algún artículo escrito sin esmero, o sin las referencias precisas, él no sólo lo corregía todo, sino que lo afinaba elegantemente, lo pulía hasta sacarle brillo y, si hacía falta, lo rees. 
cribía. Por su afán de hacer las cosas bien, Alatorre hizo de la NRFH una revista casi perfecta. Pero, como Ícaro al querer llegar al sol, el pretender acercarse demasiado a la perfección, a mi modo de ver, vulneró un poco a Antonio. Por el afán de publicar sólo artículos rigurosa y perfectamente escritos, Antonio restó tiempo de su propia obra. Claro está que este sacrificio le dio un valor singular a la revista, puesto que la $N R F H$ no sería lo que es hoy sin esta ardua y constante labor de Alatorre.

Antonio no se limitó sólo a esta tarea editorial, sino que durante varios años (de 1952 a 1959) editó también impecablemente, desde luego, la segunda revista en antigüedad de El Colegio, Historia Mexicana, aunque su nombre nunca apareciera en ella. Este tipo de tareas no pararon aquí. Lo cito nuevamente: "Me he ocupado de la corrección de "estilo" de muchos libros. Destaco entre ellos - dice Antonio- varios de Daniel Cosío Villegas, en particular los volúmenes escritos por él de la gran Historia moderna de México"s.

Dentro de las tareas de la $N R F H$, Alatorre dedicó, además, mucho tiempo a elaborar, él solo, su valiosa bibliografía. Gracias a esta labor de precisión, rigor y maestría bibliográficas de Antonio, en esta época de las computadoras y las comunicaciones instantáneas, tenemos el banco de datos más rico sobre lingüística hispánica y sobre literatura española peninsular.

En resumen, Antonio realizó dos tareas fundamentales para la cultura en lengua española: la selección y la publicación de artículos y notas de gran valor y rigor académicos y la recolección cuidadosa, amplia y casi exhaustiva de la información bibliográfica sobre los libros, artículos, notas y reseñas que tratan temas de lengua o literatura hispánicas.

Desde el mismo año de 1953, Antonio también consolidó su actividad docente. Desde esa fecha ha dado un gran número de cursos y seminarios, tanto en El Colegio de México como en la Universidad Nacional Autónoma de México. En Estados Unidos fue profesor dos veranos (1957 y 1962) en el Middlebury College. En las décadas de los años sesenta y setenta fue uno de los profesores destacados de la Universidad de Princeton, donde enseñó durante siete años, en semestres alternos. Renunció a Princeton porque prefirió vivir y concentrarse en su trabajo de México.

Como maestro, sus cursos siempre se han caracterizado por

5 Antonio Alatorre, "Curriculum vitae. Discurso de ingreso... ", Memoria de El Colegio Nacional, 1981, t. 9, núm. 4, p. 157. 
abrir el apetito de saber de todo estudiante inteligenté. Alatorre tiene la capacidad de percibir profundamente la obra de arte, pero también de saber volverla transparente y de explicar el poder de la métrica o la fuerza de la prosa para captar toda la vastedad de su significado. Igual que sus cursos, sus amenas conferencias, ya sean graciosas, irónicas, eruditas, siempre son inteligentes y han atraído a múltiples oyentes, no sólo a los especialistas.

En su faceta de traductor, Alatorre también sabe que "el hacer las cosas bien" es lo único que tiene el poder de trasladar el significado, con todos sus matices, de una lengua a otra. La traducción de Alatorre del Erasmo y España de Marcel Bataillon ${ }^{6}$ y de los libros de Antonello Gerbi ${ }^{7}$ son un modelo para los traductores de cualquier lengua. Gracias a las puntualizaciones que Antonio les pedía a los autores o las dudas que consultaba con Bataillon y con Gerbi, estos grandes hispanistas pudieron ver sus obras enriquecidas y mejoradas en español. Para la lingüística fue muy importante su traducción (en colaboración con Margit Frenk) de El lenguaje de Edward Sapir ${ }^{8}$. Una de sus primeras traducciones fue del latín, de las Heroidas de Ovidio ${ }^{9}$, que trasmite de una manera magistral el estilo, la belleza y profundidad del escritor latino.

Aunque todas sus traducciones merecerían mención especial, sólo nombro ahora las de Machado de Assis, Memorias póstumas de Blas Cubas ${ }^{10}$; Paulo Freire, Cartas a Guinea-Bissau: apuntes de una experiencia pedagógica en proceso ${ }^{11}$; Albert Beguin, El alma romántica y el sueño ${ }^{12}$; Ernst R. Curtius, Literatura europea y Edad Media

${ }^{6}$ La $1^{\text {a }}$ ed. del Fondo de Cultura Económica, México, salió el año de $1950 ;$ la $2^{\mathrm{a}}$, corregida y aumentada, se publicó en 1966 y se reimprimió en Madrid.

${ }^{7}$ De Gerbi, tradujo del italiano para el F.C.E. La disputa del Nuevo Mundo: historia de una polémica (1960) y La naturaleza de las Indias Nuevas (de Cristóbal Colón a Gonzalo Fernández de Oviedo), publicada en 1978, con adiciones del propio Alatorre.

${ }^{8}$ F.C.E., México, 1954; hay varias reediciones.

${ }^{9}$ De las Heroidas, además de la traducción, Antonio Alatorre hizo la erudita edición del texto latino, con introducción y notas para la Bibliotheca Scriptorum Graecorum et Romanorum Mexicana, UNAM, México, 1950.

${ }^{10}$ Del portugués para el F.C.E., México, 1951; fue reeditada en La Habana por Eds. R en 1964 y se reimprimió en la Col. Popular del F.C.E., México, en 1976.

${ }^{11}$ Del portugués, Siglo XXI, México, 1977.

${ }^{12}$ Del francés (en colaboración) para el Fondo de Cultura Económica, México, 1954. 
latina $^{13}$; Robert Escarpit, Contracorrientes mexicanas ${ }^{14}$; Lacan, De la psicosis en su relación con la personalidad ${ }^{15}$; entre muchas otras.

De su labor de crítico de la literatura y filólogo, el magisterio de su obra se refleja en sus múltiples artículos sobre temas variados y eruditos. Por ejemplo, sus estudios sobre la trascendencia, influencia y peripecias de varios aspectos de la poesía de los Siglos de Oro: "Para la historia de un problema: la mexicanidad de Ruiz de Alarcón"16; "Fortuna varia de un chiste gongorino" 17; "Sobre la "gran fortuna" de un soneto de Garcilaso"'18; los "Avatares barrocos del romance: de Góngora a Sor Juana Inés de la Cruz"' ${ }^{19}$; "De poética barroca hispano-portuguesa (con un ejemplo: el soneto en eco)"' ${ }^{20}$, etcétera.

Durante los años setenta y ochenta, Antonio Alatorre se ha convertido en el gran especialista en Sor Juana. Sus artículos "Para leer la Fama y obras pósthumas de Sor Juana Inés de la Cruz"'21, "Un soneto desconocido de Sor Juana"'22; "La carta de Sor Juana al P. Núñez" 23 , incluyendo el muy divulgado "Sor Juana y los hombres" 24 , son modelo de cómo debe ser una investigación rigurosa, erudita y, además, atractiva, que no sólo da una interpretación personal, sino que aporta nueva luz sobre esta genial autora del siglo XVII.

Pero a mi modo de ver, la obra que integra mejor la riqueza expresiva de Antonio - su magistral manejo de la lengua-, con su erudición, inteligencia y originalidad, es su libro Los 1001 años de la lengua española ${ }^{25}$. Antonio muestra su saber lingüístico, histórico, literario y su vastísima cultura, no sólo hispánica sino clásica, de lenguas y literaturas romances y de otras muchas euro-

${ }^{13}$ Del alemán, en colaboración con Margit Frenk, para el Fondo de Cultura Económica, México, 1955.

14 Del francés, Porrúa, México, 1957.

${ }^{15}$ Del francés para Siglo XXI, México, 1976.

${ }^{16}$ ALM, 6 (1964), 161-202.

${ }^{17}$ NRFH, 15 (1961), 483-504.

${ }^{18}$ NRFH, 24 (1975), 142-177.

${ }^{19}$ NRFH, 26 (1977), 341-459.

${ }^{20}$ Boletim de Filologia da Universidade de Lisboa, 29 (1984), 235-271. [T.

2 del Homenagem a Manuel Rodrigues Lapa].

${ }^{21}$ NRFH, 29 (1980), 428-508.

${ }^{22}$ Vuelta, 1984, núm. 94 (septiembre).

${ }^{23}$ NRFH, 35 (1987), 591-673.

${ }^{24}$ Estudios, 1986, núm. 7, 7-27.

${ }^{25} \mathrm{La} 1^{\mathrm{a}}$ ed. de Los 1001 años de la lengua española la publicó Bancomer, México, 1979; la $2^{\mathrm{a}}$, muy ampliada, F.C.E.-E1 Colegio de México, México, 1989. 
peas, con una extraordinaria claridad y sencillez. Es admirable su sabiduría al trabajar cada idea, cada frase, cada palabra para que llegue diáfana al lector, tal como él la ha planeado, con objeto de forzarlo a responder. Así logra que alguien aparentemente tan ajeno a nuestra disciplina como un ingeniero o un contador público entiendan algo lingüísticamente tan técnico como el complicadísimo fenómeno fonético llamado yod, que tan grandes desbarajustes causó en el paso del latín a las lenguas romances. Alatorre integra, tal como están integradas en la realidad, la lengua y la literatura en español en un enorme y rico universo que abarca, en una sola unidad, a España y a todo el continente americano de lengua española.

Para finalizar, puedo decir que de mi experiencia más profunda y más valedera de Antonio Alatorre como ser humano, hoy sigo percibiendo, muy acrecentada, la cercanía, la bondad y la calidez que mostró cuando me recibió, en enero de 1963, en el acogedor y agradable edificio de Guanajuato 125, para darme información sobre los nuevos cursos del primer programa de doctorado que se creó en El Colegio de México. Yo buscaba algún lugar que pudiera ayudarme a saciar una auténtica sed de aprender. Ya conocía las otras instituciones universitarias de México, privadas y públicas, y tenía también la posibilidad de estudiar en el extranjero. Pero al cruzar el umbral de aquel excepcional, pequeño y bonito edificio del Colegio la deseché, porque gracias a la calidez, combinada con la sabiduría con que fui recibida, empezó a deslumbrarme una rara especie de armonía vital que ahí se respiraba. Nunca pude ver en Alatorre el temor que inspiraba en otros estudiantes. Con dificultad acepté que la experiencia de muchos de los demás alumnos no podía ser falsa. Esto lo entendí sólo cuando más tarde observé cómo, con tanta facilidad, Antonio intimidaba a su interlocutor. Sin embargo, quien llega a ser su verdadero discípulo, aprende pronto cómo contestar, cuestionar, argumentar y fundamentar el razonamiento con argumentos difícilmente refutables.

Pero esto es sólo un detalle, porque lo importante de la enseñanza de Antonio Alatorre no es el arte de la defensa, sino la experiencia incomparable que da el arte sublime de sentir profundamente el placer estético que produce lo bien hecho: "el hacer las cosas bien", como Antonio Alatorre me enseñó a hacerlas.

Beatriz Garza Guarón El Colegio de México 
